\title{
O estresse vivenciado pela criança/família com câncer e as relações com a equipe de enfermagem
}

\section{Patrícia Barbosa da Silva}

- Enfermeira do Hospital do Câncer A. C. Camargo e do Hospital São Paulo - UNIFESP/HSP

\section{Elizabeth P. Magalhães de Almeida}

- Enfermeira do Ambulatório de Quimioterapia de Adultos do Hospital São Paulo - UNIFESP/HSP, Mestre em Enfermagem e Professora do Centro Universitário Nove de Julho.

\section{R E S U M O}

Este estudo tem como objetivo oferecer à enfermeira e à equipe de enfermagem que trabalham diretamente com a criança portadora de câncer elementos para o entendimento das reações e medos vividos pela criança sob forma de estresse e oferecer à equipe de enfermagem elementos teóricos para a melhora da relação da tríade equipe/criança/família e alternativas para uma assistência holística. Há um consenso entre as autoras mencionadas neste estudo, que relatam a visão da criança portadora de câncer sobre si mesma, seus medos, suas angústias, e a relação da família neste novo contexto de doença, tratamento, medo da morte, hospitalização e relacionamento com a equipe de enfermagem. A metodologia empregada neste estudo foi o levantamento bibliográfico de livros, revistas, teses e periódicos científicos, e o fichamento. Percebeu-se a necessidade de suporte psicológico/emocional a todos os envolvidos no processo de tratamento da criança com câncer, e a necessidade de ampliar para o graduando de enfermagem aspectos mais profundos da psicologia humana, no tocante a vida e morte e ao sofrimento, fazendo com que o profissional de enfermagem se posicione frente a estas questões e reflita, proporcionando uma assistência holística e humana à criança com câncer e sua família.

Palavras-chave: criança; câncer; estresse.

\section{A B S T R A C T}

This study has as objective offers the nurse and the nursing team that work directly with the child cancer bearer, elements for the understanding of the reactions and fears lived by the child under stress form, to offer the team of nursing theoretical elements for the improvement of the relationship of the triad equip/child/ family and alternatives for an attendance holistic. There is a consensus among the authors mentioned in this study, that you/they tell on the child's cancer bearer vision on herself, their fears, yours, and the relationship of the family in this new context of disease, treatment, fear of the death, hospitalization and relationship with the nursing team. The methodology used in this study was the bibliographical rising of books, magazines, theories and scientific newspapers, and the annotates. It was noticed the need of psychological/emotion support the all involved in the process of the child's treatment with cancer, and the need of enlarging for graduating him/it of nursing deeper aspects of the human psychology, concerning life and death and to the suffering, doing with that the nursing professional is positioned front the these subjects and contemplate, providing an attendance holistic and human the child with cancer and his/her family.

Key words: child; cancer; stress. 


\section{INTRODUÇÃO}

Com o avanço da tecnologia, a população mundial tem envelhecido cada vez mais, conseqüentemente houve um aumento na incidência das doenças crônicas degenerativas. Por isso, em todo o mundo e no Brasil, esta tendência faz crescer o número de pessoas que, entre tantas patologias existentes, desenvolvem o câncer.

O estresse vivenciado pela criança/família com câncer e as relações com a equipe de enfermagem são questões a ser exploradas e estudadas, porque a equipe de enfermagem é a que permanece mais próxima da criança e durante o maior tempo, tendo um relacionamento, tocando-a, fazendo procedimentos invasivos e dolorosos, trazendo um desconforto físico e emocional constante durante o período de tratamento, o que torna difícil obter sua confiança, mesmo que no relacionamento haja carinho e afeto.

Conhecer e compreender o mundo da criança com câncer, como ela se comunica, como demonstra medo, dor, o modo como reage, como se encontra no período de tratamento, como vê o seu mundo, ser doente e criança, como vê a equipe de enfermagem, lembrar que é apenas uma criança e precisa de amor e segurança possibilitará melhor interação e assistência para ela e sua família, na tentativa de diminuir o estresse da hospitalização e melhorar a relação e a assistência para a tríade criança, família e enfermagem.

Este estudo teve como objetivo reconhecer o estresse vivenciado durante o processo de diagnóstico e tratamento da criança portadora de câncer e sua família, além de apontar elementos teóricos para contribuir na compreensão do mundo da criança portadora de câncer; instrumentalizar a equipe de enfermagem para melhorar a relação da tríade equipe, criança e família e oferecer alternativas para uma assistência holística a criança com câncer, mediante esclarecimento teórico do mundo da criança com câncer.

\section{METODOLOGIA}

A metodologia utilizada para tal foi a revisão bibliográfica, para a qual foi realizada pesquisa em livros, revistas, teses e periódicos científicos, nos últimos 05 anos, e elaborado um fichamento.

As autoras fizeram a pesquisa bibliográfica na Biblioteca Regional de Medicina (BIREME) por meio dos artigos publicados nos últimos cinco anos sobre estresse na equipe de enfermagem e cuidado da criança com câncer, levantamento de teses de mestrado e doutorado, livros sobre esses temas e pesquisa online para dados estatísticos atualizados do Instituto Nacional do Câncer (INCA).

Após a leitura de cada texto foi realizado o fichamento, para consulta e utilização neste trabalho.

\section{REVISÃO BIBLIOGRÁFICA}

O câncer é um tumor maligno, ocasionado por distúrbio genético no qual se perde o controle normal do crescimento celular. A célula tumoral difere da célula normal, pois não obedece aos controles de proliferação, e também apresenta capacidade de migrar do seu local de origem a outros distantes, por infiltração ou por deslocamento de uma ou mais células na corrente sangüínea, formando uma nova colônia de células malignas denominada tumor secundário ou metástase ${ }^{(1)}$.

Segundo dados do Ministério da Saúde e o INCA, no adulto, em muitas situações, o surgimento do câncer está associado claramente aos fatores ambientais como fumo e câncer de pulmão; há também outros fatores considerados desencadeantes, como hábitos alimentares, irradiação solar, agentes virais e bacterianos, etilismo, medicamentos hormonais, agentes químicos, estresse e predisposição genética ${ }^{(2)}$.

Nas malignidades da infância não se observa claramente a associação relatada anteriormente, logo, prevenção é um desafio para o futuro. A ênfase atual deve ser dada ao diagnóstico precoce.

A palavra estresse é amplamente usada, por diversas áreas de conhecimento e com diferentes conotações, desde o estresse físico até o estresse psicológico no ser humano; o estresse é a resposta inespecífica do organismo a qualquer solicitação que ele tem que enfrentar, uma infecção, um grande prazer ou uma grande dor constituem agentes estressantes, e solicitam ao organismo formas de adaptações. O estresse está constantemente presente durante todas as circunstâncias da vida, com intensidades variáveis ${ }^{(3)}$.

Cada vez mais fica evidente a necessidade de desenvolver estudos e divulgar os conhecimentos sobre estresse, para auxiliar a equipe de enfermagem a instrumentalizar e saber trabalhar o estresse da criança/família com a finalidade de proporcionar um tratamento adequado frente às situações estressantes, sem causar danos físicos 
e emocionais, facilitando a assistência holística e proporcionando uma melhor qualidade de vida.

Segundo o INCA (2001), o câncer infantil corresponde a um grupo de várias doenças que têm em comum a proliferação descontrolada de células anormais e que pode ocorrer em qualquer local do organismo. Os cânceres mais freqüentes na infância são as leucemias (glóbulos brancos), tumores do sistema nervoso central e linfomas (sistema linfático). Também acometem crianças o neuroblastoma (tumor de gânglios simpáticos), tumor de Wilms (tumor renal), retinoblastoma (tumor da retina do olho), tumor germinativo (tumor das células que vão dar origem às gônodas), osteossarcoma (tumor ósseo), sarcomas (tumor de partes moles).

No Brasil, de acordo com as estimativas do INCA em 1999, ocorreram cerca de 5.238 casos novos e 2.600 óbitos por câncer entre pacientes na faixa etária pediátrica.

Foi estimado que, até o ano 2000, um em cada mil adultos jovens tenha sido tratado de alguma malignidade na infância, sendo ela a quinta causa de morte infantil em nosso país ${ }^{(4)}$.

O progresso no desenvolvimento do tratamento do câncer na infância foi espetacular nas últimas quatro décadas. Atualmente, $70 \%$ das crianças acometidas de câncer podem ser curadas, se diagnosticadas precocemente e tratadas em centros especializados. A maioria dessas crianças terá vida praticamente normal ${ }^{(5)}$.

Esses dados apontam para a necessidade de estudos referentes a traumas e transtornos que a doença causa na infância, e para o entendimento da situação em que a criança portadora do câncer se encontra, todo o estresse, medo, ansiedade, tristeza, depressão, apreensão, toda transição de estar saudável e passar a ser doente, toda vida hospitalar, mudanças de hábitos, restrições, o sofrimento da criança e da família. Há necessidade de ampliar o conhecimento desta realidade a fim de melhorar a vida desta criança e da família enquanto estiver sob os cuidados da equipe de enfermagem.

Os profissionais de enfermagem que cotidianamente vivem com a experiência de trabalhar com a criança portadora do câncer vêem seu sofrimento e evidenciam a insuficiência no seu preparo para esta questão.

O câncer pode levar a criança à morte, porém, podese também obter a cura, sendo assim, é necessário investir muito na vida enquanto ela existir, percebendo as necessidades globais da criança e atendendo-as prontamente ${ }^{(6)}$.

Este autor ainda relata: “... Geralmente os profissionais são formados e preparados para lidar com a doença e o sofrimento - inerentes a qualquer contexto de prestação de serviços na área da saúde - de uma maneira irrealista e idealizada. A ênfase na cura enquanto finalidade única e a crença na onipotência da tecnologia moderna dificultam o enfrentamento das situações vividas cotidianamente nas instituições assistenciais".

Há necessidade de desenvolver intensamente a percepção do sentido, na assistência à criança portadora de câncer, para que assim se consiga caminhar em direção a uma assistência que tente ser a que mais se aproxima do atendimento as necessidades globais das crianças envolvidas com a equipe se enfermagem.

O tratamento da criança com câncer deveria ser ampliado, para que as atenções não fossem voltadas apenas às necessidades físicas, mas também às necessidades psicológicas que a doença acarreta na vida da criança e sua família.

As coisas em que a criança acredita e o que ela sabe sobre sua doença influenciam diretamente na aceitação dos protocolos de tratamento, na adaptação à "nova" vida como doente crônico, nos efeitos relacionados ao tratamento, e no próprio curso de sua doença ${ }^{(7)}$.

FRANÇOSO ${ }^{(6)}$ faz um relato sobre o preparo da equipe de enfermagem que trabalha com a criança portadora de câncer, abordando o estresse da criança como doente, a possibilidade de morte e o relacionamento da equipe de enfermagem com esta criança.

DUPAS \& ÂNGELO ${ }^{(4)}$ relatam a visão que a criança portadora de câncer tem de si como doente, as esperanças, os medos, as frustrações, todo o estresse que a doença causa em sua vida por sentir-se incapaz de tomar uma atitude que mude o rumo dos acontecimentos. Os autores ainda alertam o profissional de enfermagem para a percepção de todo o estresse vivido por esta criança, solicitando que olhe para a criança portadora de câncer com 'os olhos da alma', para assim possibilitar a compreensão de toda a experiência vivida por ela e ampliar as dimensões e a essência do cuidado que ela necessita como ser humano.

FRANÇOSO \& VALLE ${ }^{(8)}$ alertam para o estresse vivido pela criança portadora de câncer, frente ao início do tratamento, da confirmação do diagnóstico, e esboça a 
necessidade do acompanhamento psicológico para a criança em todos os períodos que seguem a doença.

MELLO \& VALLE ${ }^{(9)}$ apresentam um estudo sobre a relação entre a família, a criança com câncer e a equipe de enfermagem; quanto à interação desta tríade, insinuam que esta relação pode ser benéfica, caso a equipe de enfermagem tenha subsídios para isto e esteja disposta e atenta para proporcionar o suporte necessário para a criança e sua família.

DUPAS, CALIRI e FRANCIOSI ${ }^{(7)}$ relatam sobre o estresse causado pela mudança que a doença proporciona na vida da criança com câncer e sua família, o estresse pelo desconforto dos longos tratamentos, a interferência que a doença causa na integridade do lar. Apontam para a necessidade de a equipe de enfermagem mostrar-se atenta para as questões que geram o estresse tanto na criança quanto na família, e saná-las ofertando atitudes e respostas concretas, corretas, compreensíveis e holísticas.

FRANÇOSO ${ }^{(6)}$ salienta que existem zonas críticas na relação entre equipe de enfermagem e a criança portadora do câncer. Esta dificuldade se refere basicamente à comunicação, ao envolvimento e ao atendimento às necessidades emocionais da criança e de seus familiares. A comunicação verbal é a mais entendida pela enfermagem, porém as crianças muitas vezes não conseguem relatar suas idéias e sentimentos de maneira clara e compreensível, o que provoca incômodo à equipe e maior sofrimento para a criança, porque sem a expressão verbal clara cria-se um estresse, uma dificuldade de estabelecer relações efetivas e direcionar a atuação da equipe. Os bebês e as crianças utilizam outros meios de demonstrar suas necessidades físicas e emocionais; seu corpo, atos e comportamento tentam nos dizer o que estão sentindo. Tentar entender estas formas de linguagem, que aparecem no dia-a-dia do trabalho da equipe de enfermagem, proporcionaria uma ampliação da compreensão das situações de estresse vividas pelas crianças portadoras de câncer e ajudaria a adequação da assistência às necessidades reais dessas crianças.

A mesma autora relata que transcender o cuidado à criança\família além do técnicolcientífico, ofertando conselho, apoio e conforto, é benigno no tratamento terapêutico e visto como arma poderosa para a melhora do estresse gerado pela doença e hospitalização. Disporse a ouvir verdadeiramente a criançalfamília e ser capaz de diagnosticar uma situação de medo ou estresse é de suma importância, pois a equipe se capacita para identificar com clareza as necessidades emergentes.

DUPAS \& ÂNGELO ${ }^{(4)}$ salientam a fundamental importância de minimizar o sofrimento da criança com câncer e respeitar a vida e o ser humano, observar a melhora física e não ocultar o aspecto emocional e psicológico.

O tratamento da criança com câncer deve abranger tanto as necessidades físicas quanto as psicológicas, de maneira igualitária, sem propensão a nenhuma das duas, pois o psicológico deve ser trabalhado a fim de que a criança seja capaz de entender e aceitar sua doença, seu grau de gravidade, e a necessidade de seu tratamento, ajudando assim a direcionar o curso da sua doença, prestando não somente uma assistência técnicolcientífica eficiente e eficaz, como também uma assistência mais humana à criança e a sua família.

Conversar e ouvir esta criança a fim de conhecer como enxerga sua doença, o seu mundo e o que ela espera dele determinará como efetivar a assistência de enfermagem individualizada.

DUPAS \& ÂNGELO ${ }^{(4)}$ descreveram como a criança portadora de câncer e sua família sentem-se diante do estresse da doença: “... vivendo uma maratona, toda a movimentação desenfreada, desesperada, realizada pela criança e pela família em busca de uma ajuda, de uma resposta para um problema que eles não são capazes de resolver sozinhos e nem com uma ajuda comum". Toda a corrida atrás de ajuda, o começar a conhecer o desconhecido, a incapacidade de controlar o que acontece, sem saber o que vai encontrar, só ter a certeza que é preciso ir em frente. Este desconhecido, os problemas que estão ocorrendo no corpo da criança são causadores de estresse.

Toda busca da cura, do diagnóstico certo, do tratamento certo, da esperança, é cansativa, às vezes cheia de desânimo, descrédito, às vezes cheia de força, esperança, alegria e vontade de que seja o caminho certo. Assim, todas estas sensações sentidas pela criança e sua família, dentro ou fora das instituições onde se encontram as equipes de enfermagem, caem como uma tempestade de emoções, causando a estas criançasłfamílias uma gangorra de estresse, ora por ser algo bom, ora por ser algo que desapontou, que não cumpriu as expectativas.

O final desta maratona; onde a ajuda é encontrada, é apenas o começo de mais uma etapa de sensações de 
ter que cumprir a pena, em que criança e família são inseridos num contexto no qual grande parte de sua experiência de ser uma criança portadora de câncer acontece.

DUPAS \& ÂNGELO ${ }^{(4)}$ relatam “... Ter que cumprir a pena é um fenômeno que retrata a experiência da criança na fase de tratamento do câncer. É assim denominado porque esta trajetória de tratamento é percebida como uma punição que lhe impõem, constituída de restrições e de aprisionamento; a criança vivencia experiências que Ihe parecem tortura, num lugar que não é o seu, mas do qual ela não tem como escapar. Ela se entrega, se submete e espera. Ela espera o tempo passar e junto dele que passe também o sofrimento, cronometra o tempo da pena, ficando à espera do alívio da dor, da liberdade, do futuro. Durante esse tempo, um desejo está sempre presente, que é o de só querer que acabe. A única liberdade que lhe é permitida experimentar é aquela do vôo alto e livre da esperança, que está bem dentro dela".

Quando estão neste contexto, a criança com câncer e sua família vivem restrições, sendo obrigados a se adequar a certos limites com a finalidade de preservar a vida frágil. Deixa de ser uma criança saudável e dona do seu corpo; passa a cuidar apenas da doença, a intrusa, colocando de lado a vida comum de criança para dar espaço apenas ao que não the fará mal, limitando a liberdade de ação e adaptando-se, abstendo-se de tudo o que pode agora the ser pernicioso.

Os autores descrevem a criança sentindo-se prisioneira internada para tratamento com obstáculos intransponíveis "... Ela sente-se reclusa, afastada do meio externo, das pessoas com as quais convivia anteriormente e sem ter como se livrar, porque além de trancada num lugar, sem saber o que vai acontecer e o porquê está lá, ela também não pode fazer nada, está algemada pelo soro, que a restringe ainda mais, ela só quer saber de sair dali, de voltar a ser e a sentir-se livre".

Quando está inserida neste contexto doença/ hospital/ tratamento, a criança portadora de câncer e sua família não têm como evitar que sensações e acontecimentos desagradáveis aconteçam, não tendo nenhum controle sobre eles; os desconfortos físicos internos, decorrentes do tratamento, e os externos, sua aparência, fazem parte do tratamento que é a esperança de vida. Assim, a criança desenvolve estratégias para aliviar o estresse e diminuir o sofrimento, ações que são de grande importância e devem ser observadas pela equipe de enfermagem como sinal de desconforto e estresse.

A distração é uma tentativa efetiva de desligamento do cotidiano estressante, com a finalidade de esquecer onde está e para que está, e deixar-se levar pelo imaginário transportando-se para um lugar melhor sem sair de onde se encontra: desejo alimentar, a necessidade de ter uma pessoa em que confie sempre por perto e a procura de outros lugares para ir dentro da instituição de saúde onde está internada para tratamento.

DUPAS \& ÂNGELO ${ }^{(4)}$ ainda referem que mesmo com todo o estresse sofrido pela criança portadora de câncer, ela persiste sem desistir, porque acredita que no final tudo vai melhorar, e isto a faz manter-se forte superando todas as dificuldades. A crença em Deus e a motivação recebida da família e equipe de enfermagem Ihe dão suporte para continuar e apoio para não desistir.

O modo como a equipe de enfermagem interage com a criança/família possibilita a diminuição do estresse, informando-lhes sempre do que será feito, fazendo com que surpresas desagradáveis não aconteçam e proporcionando à equipe a confiança da criança em relação ao cuidador. Oferecer-lhe incentivo verbal ou material quando está desanimada e abatida, fazê-la interagir com outras crianças e pensar positivo no momento em que demonstra estar sem forças para continuar é uma forma de trocar as situações tristes por algo que a torne feliz, barganhar o desejo da criança é uma forma saudável de encaminhá-la novamente para a esperança e a auto-ajuda.

Conforme o estudo de DUPAS \& ÂNGELO (4), “... é preciso focalizar os olhos da alma para conseguir enxergar para além do sofrimento, da vulnerabilidade, da dor". É necessário que a equipe de enfermagem ofereça o apoio à criança com câncer a fim de fazer que sua força interior ajude a suportar o sofrimento e a ter esperanças para conseguir atingir o objetivo da cura. Certamente a criança com câncer e sua família apresentarão períodos de desesperança, porém não sucumbirão ao sofrimento.

Ainda em seu estudo, estas autoras relatam que o tratamento da criança com câncer “... ultrapassa as dimensões biopsicossociais-emocionais, indo até a dimensão espiritual...", não sendo fácil a equipe de enfermagem colocar-se frente à criança. É necessário percebê-la como pessoa e apoiá-la efetivamente, 
sugerindo que este seja, talvez, o primeiro passo para estabelecer uma interação que resulte em uma melhor qualidade do cuidado oferecido pela equipe de enfermagem.

A criança com câncer tem seus hábitos mudados mesmo antes da confirmação da sua doença. Ela percebe que algo não vai bem com seu corpo e ainda sente as modificações de comportamento das pessoas que a cercam. Quando é confirmado o diagnóstico, o estresse é acentuado. O primeiro ano de tratamento, incluindo o diagnóstico, é fator de extremo estresse, que pode ser temporário ou perdurar além dos limites da doença e tratamento.

FRANÇOSO \& VALLE ${ }^{(8)}$ relatam que o estresse é desencadeado na criança pelos diversos tratamentos realizados e pela percepção da criança da experiência de ter o câncer.

Além dos diversos tipos de tratamento medicamentoso e hospitalar, há necessidade de um acompanhamento psicossocial, tentando voltar-se ao indivíduo, criança e a família, como um todo, e não à doença, porque existe um sofrimento muito grande da criança e de sua família, tentando encarar a doença, a possível e imprevisível morte, as deficiências que eventualmente ficarão como seqüelas, as mutilações, gerando um estado de estresse. Por isso, as intervenções psicossociais por meio de vários tipos de terapias (individual ou em grupo) tentam aliviar o sofrimento que a doença e o período de tratamento trazem, na tentativa de minimizar os prejuízos no desenvolvimento global da criança e garantir a qualidade de vida no decorrer e após o final do tratamento, para que a criança possa socializar-se novamente.

Ainda conforme o estudo de FRANÇOSO \& VALLE ${ }^{(8)}$, as crianças portadoras de câncer, além do estresse causado pelas preocupações com o tratamento, a hospitalização e a morte, também se preocupavam com a escola, a vida social, a dieta, a família e o futuro.

Os mesmos autores confirmam o que outros estudos evidenciaram: o estresse da criança com câncer e sua família está ligado diretamente com o medo da morte, o tratamento e seus efeitos colaterais, o medo do futuro, os sentimentos de insegurança, medo, desespero e perda, que invadem as suas vidas.

Quando a suspeita da doença torna-se o diagnóstico de câncer, a família vivencia inúmeras dificuldades, geradoras de estresse; ajudar a criança com câncer a transpor as situações de sofrimento físico e emocional que a doença acarreta e manter a interação da família faz parte do dia-a-dia que a equipe de enfermagem vivencia no contexto hospitalar.

A equipe de saúde pode oferecer ajuda não somente técnica no tratamento da criança com câncer, mas também emocional, ouvindo a família e a criança, manifestando solidariedade ou através do apoio e compreensão. Isso trará grande benefício neste momento tão crucial que é o diagnóstico e o tratamento.

Como o câncer pode apresentar períodos de remissões e recaídas, a dinâmica familiar se altera rapidamente, transformando a vida numa gangorra de estresse, com períodos de otimismo e esperança e outros de desestruturação total, angústia e desespero.

MELLO \& VALLE ${ }^{(9)}$ relatam que, diferentemente da criança, para a família há outros fatores geradores de estresse. Além da preocupação com tratamento, doença e morte, há a preocupação com a casa e com outros filhos, faltas, licenças ou afastamento do trabalho, ciúmes dos outros filhos, cansaço físico e emocional e problemas de ordem conjugal.

Ainda em seu estudo relatam que muitas vezes a família é quem necessita mais de ajuda do que a própria criança para aceitar a doença, e a equipe de enfermagem deve estar atenta para intervir junto à família assegurando o acompanhamento das suas necessidades. O preparo da equipe compreende, além da técnica, habilidades de relacionamento interpessoal e de consideração pela criança e sua família como seres humanos.

DUPAS, CALIRI e FRANCIOSI ${ }^{(7)}$, em estudo sobre a assistência da equipe de enfermagem prestada à família da criança com câncer, enfocam itens relevantes ao tratamento. Enquanto a criança mantém-se dentro do quadro de doente com câncer, as reações de estresse são vistas e percebidas pela equipe de saúde, ficando assim evidenciado por expressões, gestos, palavras e atitudes todo o estresse que a família e a criança sentem a partir da suspeita da doença, a confirmação do diagnóstico e o curso do tratamento e hospitalização.

No início o desespero, o choque, com que a família recebe o diagnóstico é claro e perceptível a qualquer membro da equipe. Com a notícia do diagnóstico do câncer, pensa-se que a morte é certa, visto que a crença de que o câncer não tem cura é ainda bastante difundida 
entre a sociedade fora do contexto da saúde. A família sente-se ansiosa, desesperada, com medo, revolta-se com a situação, sente-se culpada e desorientada, fica por vezes paralisada, sem ação e apresenta atitudes agressivas. Iniciase neste momento o caminho de incertezas, dúvidas e sofrimento, tudo o que em sua vida era normal, rotineiro e previsível passou a ser desestruturado, desordenado e imprevisível, gerando um estresse enorme.

As autoras ainda citam que o investimento de toda a família é muito grande para que o tratamento ocorra. Separações, interrupções de atividades e preocupações em manter o restante da família também são geradores de estresse, normalmente porque um familiar acompanha a criança no tratamento e o outro tenta manter o emprego. Dessa forma, a desestruturação familiar ocorre pois aquele que acompanha fica voltado quase que inteiramente para a criança doente, e o que sustenta a casa para o restante da família, gerando um estresse físico e emocional bastante sobrecarregado.

À medida que o tratamento vai se prolongando e a criança apresenta períodos de melhora, ela e a família vão tentando se adaptar à equipe de enfermagem e de saúde e à instituição, e tentam aceitar a doença não como sinal de morte iminente, mas como algo que possa evoluir para a cura; assim, vai surgindo a esperança, que também é sentida como geradora de estresse.

Num primeiro momento, quando o diagnóstico é feito, a família sente-se atordoada e não consegue processar um volume de informações muito grande, então há necessidade de alguém sempre por perto, mostrando sempre que tudo será feito para que a criança obtenha os melhores resultados no tratamento. Neste momento de estresse a família precisa muito mais de apoio, carinho, atenção do que a própria criança em si, porque ela será a base desta criança; por inúmeras vezes, passará toda a informação sobre o tratamento a ser feito e os procedimentos realizados, e toda a segurança de que a criança precisa para confiar na equipe de enfermagem. Na medida em que o tempo for passando, a família anseia por mais informações sobre a doença, prognóstico, e como agir com a criança, porque será por inúmeras vezes o elo de ligação entre a criança e a equipe de enfermagem. Todo este estresse gerado poderá ser sanado, em grande parte, pela equipe de enfermagem, quando esta perceber os sinais de estresse da família, minimizando assim o estresse da criança, facilitando seu tratamento e sua interação com a equipe.

O processo de tratamento para a criança e a família é estressante, cada dia um sintoma novo, uma reação do organismo que debilita, uma dor, uma invasão, uma expectativa de que tudo dê certo, uma esperança oscilante.

O cuidar inclui ajudar o físico, o biológico e também o psicológico. O cuidado da criança com câncer e sua família é grande e complicado, e deverá ser compartilhado por outros membros da equipe de saúde multiprofissional, porque a equipe de enfermagem pode enfrentar situações com as quais nem sempre saberá como lidar. Assim, na dimensão do cuidado está inserida a ajuda; nesta relação íntima a equipe de enfermagem vive a expectativa de aliviar a dor, dar conforto físico e emocional, na tentativa de aliviar o estresse desta criança, ouvir, conversar, falar sempre a verdade, acariciar, brincar, respeitar as vontades, estar sempre presente, encorajar, dedicar-se, sorrir sempre, ficar sempre junto. Ouvir o desabafo da criança ou da família é uma maneira de a equipe de enfermagem conferir apoio.

Apoiar a fé, seja ela qual for, é uma forma de fazê-los sentir-se fortes e acreditando que "Algo Superior" pode tudo resgatando-lhes a esperança.

DUPAS, CALIRI, FRANCIOSI (7) ainda relatam os fatores que desencadeiam o estresse para a equipe de enfermagem.

A importância que o profissional dedica à criança, à família e à doença irá definir o tipo de cuidado oferecido. Quando o profissional de enfermagem percebe que o câncer é uma doença que acomete não somente o adulto, que pode ter cura, e que a guerra precisa ser vencida, ele passa a necessitar de mais dados sobre o tema.

A equipe de enfermagem aprende a lidar com o câncer, mas quando este acomete uma criança, a aceitação da doença é mais resistente pela a equipe, porque ela está sendo privada de viver a vida, a infância e de gozar do melhor que a idade pode lhe ofertar, tendo por vezes que enfrentar a morte. Isto causa na equipe a necessidade de adaptações, para que o profissional possa continuar a cuidar com eficiência.

A criança, a família e a equipe vivem sob constante estresse. Lidar com o câncer é de certa forma desgastante, não somente para criança e família, mas também para a equipe. 
O tempo de contato com a criança e a patologia define a intensidade do estresse gerado na equipe de enfermagem, no tocante ao enfrentamento da doença e da morte; quanto mais tempo em contato com a criança, mais se sente o acontecimento, pois a equipe acompanha cada progresso e cada piora da criança sob seus cuidados, criando por vezes, um vínculo afetivo.

A equipe relaciona experiências anteriores às novas, e normalmente traça um paralelo com diagnósticos e prognósticos, mesmo quando não há mais o que se fazer para a cura. Cuidar, aliviar a dor e ter esperança são maneiras de diminuir o estresse.

O trabalho onde o território é a constante luta pela vida contra a morte pode trazer problemas emocionais para os profissionais de enfermagem, tanto quanto para a criança e a família, notando-se a necessidade de ajuda emocional para todos.

\section{CONSIDERAÇÕES FINAIS}

Entender as expressões e reações de estresse da criança com câncer e sua família possibilitará uma melhor adequação e postura da equipe de enfermagem perante a criança que está sob seus cuidados. A falta de habilidade da equipe de saúde em lidar com os problemas relacionados ao estresse dos portadores de câncer e sua família tem relação com a deficiência da formação que estes profissionais recebem durante o período da graduação, ocasionando uma impotência frente aos pacientes. Lidar com sentimentos causa na equipe desajustes e provoca alterações emocionais que interferem em sua atuação técnica.

O profissional necessita conscientizar-se de sua condição humana, de suas emoções e medos, precisa compreender o sentido da vida e da morte, suas limitações. Deve compreender e aceitar as emoções de cada indivíduo/paciente/família e saber que inevitavelmente todas estas emoções serão transferidas para o paciente durante seu período de tratamento.

Portanto, há necessidade de priorizar o preparo da equipe, no sentido de dar-Ihe suporte teórico-científico tanto quanto psicológico para que possa atuar de maneira holística, para que este seja mais um método de trabalho a fim de facilitar o convívio com a criança com câncer e sua família, trazendo benefícios para todos.
Há necessidade também de enfatizar a abordagem de uma equipe de psicólogos e terapeutas, tanto para orientar a criança e trabalhar toda a problemática doença, temores, tratamento, internação, hospital, procedimentos, morte, futuro e família, quanto para a equipe, na tentativa de orientá-la a lidar com as dificuldades apresentadas no dia-a-dia, por meio de seminários, palestras, discussões, que passam a fazer parte de sua rotina.

A contribuição da Psicologia no tocante a estas questões é fundamental, pois traz a possibilidade de lançar luz sobre aspectos importantes e fundamentais da assistência à criança com câncer e sua família, dando sentido às experiências vividas, direcionando sentimentos, emoções e afeto, para a melhora da qualidade das relações construídas no contexto hospitalar.

Entender o estresse da criança com câncer e sua família e conferir um cuidado holístico é de suma importância, portanto "colocar-se no lugar do outro", seja da criança ou do familiar. Entender que a criança e a família tornam-se uma única unidade diminuirá a margem de erros quando tentarmos oferecer o cuidado e a ajuda emocional, já que ainda falta na graduação do enfermeiro um suporte melhor para os futuros profissionais de enfermagem no contexto psicológico.

Neste estudo, percebeu-se que o estresse vivido pela criança com câncer durante seu período de doença e tratamento afeta não somente o doente e a família, mas também toda a equipe de enfermagem e de saúde, porque este processo envolve tempo e, com o tempo, acontece o envolvimento profissional e emocional, gerando aí uma tríade: criança, família e equipe de enfermagem.

Este estudo aponta alguns elementos geradores de estresse da criança e da família como doente e sob tratamento; oferece à equipe de enfermagem uma visão teórica dos comportamentos, auxiliando-a a elaborar alternativas para a assistência adequada a cada um individualmente.

Mediante a compreensão teórica dos elementos geradores de estresse, a equipe capacita-se para melhorar efetivamente a relação humana da tríade equipe, criança e família.

Cabe ressaltar ainda a grande necessidade de ampliar os estudos na área de oncologia infantil, pois nossa literatura é escassa, contrastando com o índice da doença em nosso país, o que é um pesar. 


\section{BIBLIOGRAFIA}

1. CAMARGO, B, Oncogenese. In: AYOUB, A.C.; FONTES, A. N.C.; SILVA M.A.A.; ALVES, N.C.R.; GIGLIETTE, P.; SILVA, Y.B. Planejamento: o cuidar na enfermagem oncológica. São Paulo: Gemar, 2000 p.39-41.

2. INSTITUTO NACIONAL DO CÂNCER. Câncer Infantil. 2001. On Line. Disponível na Internet. www.inca.org.br / câncer/tipos/infantil.html.

3. MANUILA, L.; MANUILA, A.; NICOLIN, M. Dicionário Médico Andrei. 7. ed. São Paulo: Organização Andrei.

4. DUPAS, G.; ANGELO, M., Buscando superar o sofrimento impulsionado pela esperança: a experiência da criança com câncer. Acta-Oncol. Bras; 17, n. 3, p. 99-208, 1977.

5. INSTITUTO NACIONAL DO CÂNCER. MINISTÉRIO DA SAÚDE, Epidemiologia do Câncer - Epidemiologia dos Tumores da Criança e do Adolescente. 2001. On Line. Disponível na Internet. www.inca.org.br /epidemiologia/ criança_e_adolescente.html
6. FRANÇOSO, L. P. C., Reflexões sobre o preparo do enfermeiro na área de oncologia pediátrica. Revista LatinoAmericana de Enfermagem. v.4, n.3, p. 41-48 dez. 1996.

7. DUPAS, G.; CALIRI, M. H. L.; FRANCIOSI, M.C., Percepções de enfermeiras de uma instituição hospitalar sobre a assistência prestada à família e a criança portadora de câncer. Revista Brasileira Cancerol, v.44, n.4, p. 327-34, out./dez. 1998.

8. FRANÇOSO, L. P. C.; VALLE, E. R. M. A criança com câncer estudo preliminar. Pediatri.Mas. v.35, n.5, p. 320-331, 1999.

9. MELO, L. L.; VALLE, E. R.M. Equipe de enfermagem, criança com câncer e sua família: uma relação possível.

Pediatri.Mod. v. 35, n. 12, p. 970-2, 1999. 